\title{
Evidence for gene $\times$ smoking exposure interactions in a genome-wide linkage screen of asthma and bronchial hyper-responsiveness in EGEA families
}

\author{
Marie-Hélène Dizier*,1,2, Emmanuelle Bouzigon ${ }^{3,4}$, Michel Guilloud-Bataille ${ }^{1,2}$, \\ Valérie Siroux ${ }^{5}$, Arnaud Lemainque ${ }^{6}$, Anne Boland $^{6}$, Mark Lathrop $^{6}$ and Florence Demenais ${ }^{3,4}$ \\ ${ }^{1}$ INSERM, U535, Villejuif, France; ${ }^{2}$ Université Paris-Sud, IFR69, Villejuif, France; ${ }^{3}$ INSERM, U794, Evry, France; \\ ${ }^{4}$ Université d'Evry, Evry, France; ${ }^{5}$ INSERM, U578, Grenoble, France; ${ }^{6}$ Centre National de Génotypage, Evry, France
}

Asthma and bronchial hyper-responsiveness (BHR), an asthma-related phenotype, result from many genetic (G) and environmental (E) factors. Passive exposure to tobacco smoke (ETS) in early life is one of these risk factors. Following a genome scan for asthma and associated phenotypes conducted in 295 French Epidemiological study on the Genetics and Environment of Asthma, our present aim was to investigate interactions between genetic susceptibility to asthma and to BHR with passive ETS using two different methods: the predivided sample test (PST) and the mean interaction test (MIT). PST and MIT consider the identical by descent (identity by descent) distribution at all markers in affected sib-pairs with 2, 1 or 0 sib(s) exposed to ETS. While the PST allows detection of both linkage and G $\times E$ interaction, the MIT tests for linkage by taking into account a possible interaction. Among the six regions detected at $P \leq 0.005$, three of them (1q43-q44, 4q34, 17p11) were revealed by both PST and MIT for BHR. The three other regions were detected by only one method: 5 p15 for BHR using PST; 14q32 and 17q21 for asthma using MIT, underlying the importance of using concomitantly different approaches. None of these regions was revealed for asthma and bronchial responsiveness by previous linkage analyses of these data, supporting the idea that taking into account gene-environment interactions can substantially increase power of linkage detection. Our results also showed evidence for $G \times E T S$ interactions underlying BHR in all four regions detected by PST.

European Journal of Human Genetics (2007) 15, 810-815; doi:10.1038/sj.ejhg.5201830; published online 11 April 2007

Keywords: genetic linkage; passive smoking exposure; interaction; asthma; bronchial hyper-responsiveness

Introduction

Asthma is a common respiratory disease characterized by airway inflammation, reversible airflow obstruction and bronchial hyper-responsiveness (BHR) to various environmental stimuli. Asthma is a complex and heterogeneous

*Correspondence: Dr M-H Dizier, Hôpital Paul Brousse, Bâtiment Leriche, BP 1000, 94817 Villejuif Cedex, France.

Tel: + 331455953 91; Fax: + 331455953 31;

E-mail: dizier@vjf.inserm.fr

Received 26 September 2006; revised 22 February 2007; accepted 6 March 2007; published online 11 April 2007 disorder caused by multiple genetic and environmental factors. Candidate-gene and genome-wide linkage studies, carried out over the past 10 years, pointed to at least 20 regions linked to asthma and asthma-related phenotypes, $^{1,2}$ suggesting that many genes with relatively small effects might be involved. Although a few genes have been characterized by positional cloning, ${ }^{2}$ localizing and identifying new genes remain challenging.

Among the many environmental factors that have been reported to be associated with asthma or to exacerbate asthma symptoms, maternal smoking during pregnancy and exposure to tobacco smoke (ETS) in early life have 
been found to be important risk factors for asthma and BHR. $^{3-5} \mathrm{G}$ (gene) $\times$ ETS interaction underlying susceptibility to asthma and asthma-related phenotypes have been evidenced by association studies with candidate genes including ADRB2 ( $\beta 2$-adrenergic receptor), ${ }^{6}$ GSTM1 (glutathione S-transferase M1) ${ }^{7,8}$ and GSTT1 (glutathione S-transferase $\mathrm{T} 1)^{7}$ genes and more recently in the context of two genome-wide scans in American and Dutch families.9,10 These studies as well as simulation studies have shown that taking into account $\mathrm{G} \times \mathrm{E}$ (Environment) interaction in genetic analysis cannot only lead to detection of such interaction but can also increase power to detect linkage (or association with candidate genes) which would not be revealed by classical approaches. ${ }^{11,12}$

A genome scan for asthma and atopy-associated phenotypes $^{13,14}$ was recently carried out in a sample of 295 French families ascertained through an asthmatic subject, as part of the EGEA study (Epidemiological study on the Genetics and Environment of Asthma). This scan showed evidence for linkage of a few regions to asthma-related phenotypes but revealed weaker signals for asthma on 1 p31 and for bronchial responsiveness on 3q21. Using the same data, the aim of the present study was to include information on passive smoking exposure during early life and/or in-utero in genome-wide linkage analyses of asthma and BHR and to test for $\mathrm{G} \times$ ETS interaction. We used two statistical methods, the predivided sample test (PST) ${ }^{15}$ and the mean interaction test (MIT), ${ }^{16}$ which differed from the approaches used by the American and Dutch screens ${ }^{9,10}$ and have been shown, through simulations, to increase power to detect linkage in presence of $\mathrm{G} \times \mathrm{E}$ interaction under various genetic models. ${ }^{11}$

\section{Materials and methods Family data}

The main EGEA sample included 348 nuclear families selected through one asthmatic proband. An additional sample of 40 nuclear families was selected through two asthmatic sibs to increase the number of informative families for linkage analyses of asthma. Inclusion criteria met by the probands were described elsewhere. ${ }^{17}$ Ethical committee approved the protocol and subjects signed informed consent forms.

\section{Phenotypes analyzed}

Information on respiratory and allergic symptoms, medical history and environmental factors including exposure to tobacco smoking was collected using a standardized questionnaire. ${ }^{18}$ Various biological and physiological tests were also performed. ${ }^{17}$ Asthma was defined using the same criteria as in previous EGEA linkage scans: ${ }^{13,14}$ positive answer to at least one of the two questions: 1/Have you ever had attacks of breathlessness at rest with wheezing? 2/Have you ever had an attack of asthma? associated with either the presence of bronchial hyper-responsiveness, hospitalization for asthma in life or asthma therapy.

The BHR phenotype, used in the present analysis, was defined by the PD20: a fall in baseline FEV1 (forced expiratory volume at $1 \mathrm{~s}$ ) $\geq 20 \%$ at $4 \mathrm{mg} / \mathrm{ml}$ methacholine. The protocol of the methacholine challenge test has been described in detail elsewhere. ${ }^{17}$

The passive ETS in early-childhood phenotype was defined by answers to different questions in adults and children indicated as follows: (1) for an adult, by a positive answer to the question: did your mother or your father smoke during your early-childhood? (2) for a child, by a positive answer to the question asked to the child's mother (or father): did you or the father (or the mother) of your child smoke when your child was less than 2 years old?

Our aim was also to consider an ETS phenotype defined by passive ETS in-utero and/or in early childhood. However, the distribution of exposed/unexposed siblings according to this ETS phenotype was similar to the distribution observed when using the first ETS phenotype (i.e. ignoring the in-utero exposure). Thus, only results corresponding to passive ETS in early childhood are presented.

\section{Genotypes}

Genotyping of 396 microsatellites (378 autosomal markers) was performed in EGEA families with at least two sibs with DNA available. These markers were distributed at an average marker density of 10 centimorgan (cM) and had an average heterozygosity of $75 \%$. Rigorous genotype quality control was performed, as described previously. ${ }^{13,14}$ Following our previous scan, ${ }^{13,14}$ additional markers were genotyped for fine mapping in the regions that revealed potential linkage. A total of 185 additional markers, distributed across 12 chromosomes (chromosomes 1-3, 5-7, 9, 11-13, 17 and 21), were included in the present analyses. As for the original scan, these markers were evaluated for Mendelian inconsistencies using Pedcheck ${ }^{19}$ and double recombinants were identified using Mendel. ${ }^{20}$ After this genotyping quality control, the present samples included 110 families with at least two asthmatics and 89 families with at least two sibs with BHR.

\section{Statistical methods}

IBD sharing under $\boldsymbol{G} \times \boldsymbol{E}$ interaction The sharing of marker alleles identical by descent (IBD) among affected sib-pairs is classically used in linkage analysis between a disease and a marker and allows to conclude in favor of linkage if the observed IBD distribution differs significantly from that expected under the null hypothesis of independence of segregation of disease and marker. This comparison can be made with the MLS statistic ${ }^{21}$ which provides maximum likelihood estimates of the proportions of sib-pairs with 2,1 , or 0 marker alleles IBD (denoted respectively $z_{2}, z_{1}$ and $z_{0}$ ), given the observed marker genotypes. 
Note that the maximum likelihood statistic (MLS) method usually assumes that the IBD proportions, $z_{2}, z_{1}$ and $z_{0}$, are constrained within a triangle so that $2 z_{0} \leq z_{1} \leq 0.5$, referred as the triangle constraints. ${ }^{22,23}$ Under linkage, the IBD distribution depends on the parameters of the susceptibility gene to which the marker is linked, that is the allelic frequency and the genotype relative risks. When there is $\mathrm{G} \times \mathrm{E}$ interaction, these latter parameters differ according to the presence or absence of E, consequently the IBD distribution may also differ according to the number of $\operatorname{sib}(s)(2,1$ or 0$)$ exposed in the pair. Such heterogeneity in the IBD distribution among sib-pairs is used to detect $\mathrm{G} \times \mathrm{E}$ interaction by the two PST and MIT methods.

The predivided sample test Under the null hypothesis of absence of $\mathrm{G} \times \mathrm{E}$ interaction, the IBD vectors $Z\left(z_{2}, z_{1}, z_{0}\right)$ estimated among affected sib-pairs with 2 or 0 sibs exposed (EE and UU pairs, respectively) are expected to be equal. Therefore, the null hypothesis can be tested by $-2\left(\operatorname{Ln}\left(L\left(Z_{\mathrm{EE}}\right) L\left(Z_{\mathrm{UU}}\right) / L(Z)\right)\right)$ which follows a $\chi^{2}$ distribution with $2 \mathrm{df}^{15}$ where $L\left(Z_{\mathrm{EE}}\right), L\left(Z_{\mathrm{UU}}\right)$ and $L(Z)$ are the likelihood of the parameter vectors, $Z_{\mathrm{EE}}, Z_{\mathrm{UU}}$ and $Z$ estimated respectively in EE and UU sib-pairs and in the whole sample (made of these two subsamples). Since the parameter vectors $Z$ are estimated using the triangle constraints, the PST statistic does not follow a $\chi^{2}$ with 2 df as would do the classical PST. ${ }^{15}$ Empirical $P$-values estimated by bootstrap analyses showed that the PST distribution under such constraints was close to a $\chi^{2}$ distribution with $1 \mathrm{df}$.

The mean interaction test Gauderman and Siegmund ${ }^{16}$ proposed an extension of the mean sharing test to account for $\mathrm{G} \times \mathrm{E}$ interaction. The mean sharing test uses the proportion of alleles shared IBD among affected sib-pairs, $\pi$, which is expected to be equal to 0.5 under the null hypothesis of no linkage. In this extension, $\pi$ is estimated in the different groups of affected sib-pairs (EE, EU and UU for 2, 1 and 0 exposed sibs respectively). This method is based on the regression model $\pi_{\mathrm{i}}=\pi+\beta\left(X_{\mathrm{i}}-X\right)+\varepsilon_{\mathrm{i}}$, where $\pi$ is the intercept and $\beta$ the regression coefficient for the exposure $\left(X_{\mathrm{i}}\right.$ the covariate of exposure being centered on its mean $X$ ). Different coding schemes were proposed for $X,{ }^{16}$ but, as shown by our simulations, they led to similar results $^{11}$ under most $\mathrm{G} \times \mathrm{E}$ interaction models. Thus, to minimize the number of tests performed, we chose one of these coding schemes that included two variables (XEE and XEU) contrasting EE and EU sib-pairs respectively to UU pairs. The null hypothesis of absence of linkage was tested by the likelihood ratio test, $T_{\pi \beta}=-2(\operatorname{Ln}\{L(\pi=0.5, \beta=0)\}-$ $\operatorname{Ln}\{L(\pi, \beta)\})$. The alternative hypothesis is assumed to be one-sided for $\pi>0.5$, and two-sided for $\beta$. The distribution of $T$ is a (50:50) mixture distribution of $\chi_{p}^{2}$ and $\chi_{p+1}^{2}$, with $p$ being the number of regression coefficients (here equal to 2). The alternative hypothesis corresponds to linkage with or without $\mathrm{G} \times \mathrm{E}$ interaction.
Note that the MIT takes into account $\mathrm{G} \times \mathrm{E}$ interaction when testing for linkage but does not test for $G \times E$, while the PST allows detection of both linkage and $\mathrm{G} \times \mathrm{E}$. In the absence of $\mathrm{G} \times \mathrm{E}$, the PST cannot detect linkage, while the MIT can but with lower power than the classical mean test, due to additional parameters for the exposure variables, and consequently higher degrees of freedom.

For both PST and MIT methods, a multipoint approach was used to estimate the IBD sharing ( $Z$ vectors), taking into account the information provided by the entire set of chromosome markers.

\section{Results}

Among the 726 genotyped siblings of the 295 EGEA families selected through one asthmatic subject, the distribution of clinical characteristics are given separately in exposed and in unexposed sibs (Table 1). Distribution of sex and age were similar in the two groups. There was also no difference of BHR frequency between exposed and unexposed siblings, while the frequency of asthma was slightly higher in unexposed sibs than in the exposed ones but not significantly. This might be explained by under-reporting of smoking habits by mothers of asthmatic children when questioned on their children's passive ETS. $^{24}$

Table 2 gives the distribution of genotyped affected sib-pairs for asthma and BHR, according to their exposure status (EE, EU, UU).

Table 3 shows the regions detected for asthma and BHR at a $P$-value $\leq 0.005$ using either PST or MIT approach. For asthma, no region was revealed at that level by the PST, while the two following regions were detected by the MIT: 14q32 $(P=0.0009)$ and $17 \mathrm{q} 21(P=0.0003)$. Four regions were revealed for BHR at the $0.5 \%$ level. Three of these regions were detected by both PST and MIT approaches: 1q43-q44 $(P=0.005$ and 0.0009$), 4 q 34(P=0.003$ and $0.002)$ and $17 \mathrm{p} 11(P=0.002$ and 0.002$)$. Evidence for linkage to $5 \mathrm{p} 15(P=0.003)$ was found by PST only.

Table 1 Descriptive characteristics of the 726 genotyped siblings of the 295 EGEA families according to passive ETS in early childhood

\begin{tabular}{lll}
\hline & \multicolumn{1}{c}{$E^{\mathrm{a}}$} & \multicolumn{1}{c}{$U^{\mathrm{a}}$} \\
& $\mathrm{n}=400^{\mathrm{b}}$ & $\mathrm{n}=305^{\mathrm{b}}$ \\
\hline Age (mean, [SD]) & $17.4[7.9]$ & $14.2[6.8]$ \\
Sex (\% males) & 52 & 55 \\
Asthma (\%) & 50 & 59 \\
BHR (\%) & 63 & 64 \\
\hline
\end{tabular}

Abbreviations: BHR, bronchial hyper-responsiveness; EGEA, Epidemiological study on the Genetics and Environment of Asthma; ETS, exposure to tobacco smoke.

${ }^{\mathrm{a}} \mathrm{E}$, exposed; $\mathrm{U}$, unexposed.

bInformation on ETS exposure was missing for 21 sibs. 
In the four regions revealed by the PST approach, there was evidence for $\mathrm{G} \times$ ETS interaction underlying susceptibility to BHR. In two of them, 1q43-q44 and 4q34, the excess of IBD sharing was only observed in affected sibpairs with both sibs exposed $\left(z_{2}=0.44\right.$ and 0.34 respectively), indicating these regions may contain genetic factors that influence BHR only in presence of ETS. The opposite situation was observed for the $5 \mathrm{p} 15$ and $17 \mathrm{p} 11$ regions with an excess of IBD sharing when both sibs were unexposed $\left(z_{2}=0.46\right.$ and 0.54 respectively), suggesting involvement of genetic factors underlying BHR in absence of ETS.

\section{Discussion}

Taking into account gene-environment interactions in genetic analysis of a complex and heterogeneous disease such as asthma, although scarcely done, appears particularly relevant. The present genome-wide linkage analysis, that incorporated information on passive ETS during early life, led to detect two regions linked to asthma and four regions linked to BHR that were not revealed by classical linkage analysis of the same data. This was achieved by use of the PST and MIT methods, which both enabled to conduct an overall test for linkage (and heterogeneity for

Table 2 Distribution of sib-pairs affected with asthma and BHR according to the number of sibs exposed for passive ETS in early childhood

\begin{tabular}{ll}
\hline No of asthmatic sib-pairs & \\
EE & \\
EU & 10 \\
UU & 64 \\
No of BHR sib-pairs & \\
EE & 53 \\
EU & 10 \\
UU & 49 \\
\hline
\end{tabular}

Abbreviations: BHR, bronchial hyper-responsiveness; ETS, exposure to tobacco smoke.

${ }^{\mathrm{a}} \mathrm{EE}, \mathrm{EU}, \mathrm{UU}: 2,1,0$ sibs exposed respectively.
PST) while taking into account the exposure status of affected sib-pairs. These methods differed from the approaches used by the two previous screens ${ }^{9,10}$ investigating $\mathrm{G} \times$ ETS in which linkage analyses were conducted separately in exposed and unexposed families. Moreover, $\mathrm{G} \times$ ETS interaction underlying BHR was evidenced in four regions by use of the PST. The present study took also advantage of the extensively documented information on environmental exposures in the EGEA study, regarding both adults and children at different time periods.

Four regions, 1q43-q44, 4q34, 5p15 and 17p11, potentially involved in genetic susceptibility to BHR interacting with ETS in early life, were detected by the PST approach. The PST approach indicated that two of these regions may contain genetic factors that influence BHR in presence of ETS while, in the two other regions, genes may play a role in absence of ETS. Three of these four regions, (1q43-q44, $4 q 34$ and 17p11) were also revealed by the MIT. In contrast, the 5 p15 region was not found significant by the MIT. This latter result may be due to the greater power of the PST over the MIT, particularly under some disease models in which presence (or absence) of the environmental factor changes the direction of the genetic effect, as shown by our previous simulations. ${ }^{11}$ Conversely, the $14 q 32$ and 17q21 regions were detected for asthma by the MIT but not by the PST. These latter results might indicate presence of linkage without $\mathrm{G} \times$ ETS interaction in these two regions. However, linkage analyses of asthma in the same EGEA data, ignoring $\mathrm{G} \times \mathrm{E}$ interaction, did not show evidence for linkage to these regions. ${ }^{14}$ These results might be also explained by a higher power of MIT than the PST approach and linkage analysis ignoring $\mathrm{G} \times \mathrm{E}$, under some models of $\mathrm{G} \times \mathrm{E}$ interaction in which presence (or absence) of the environmental factor cancels the genetic effect. ${ }^{11}$ All these results underline the importance of using concomitantly different approaches to test for linkage in presence of $\mathrm{G} \times \mathrm{E}$ when the underlying model is unknown. Indeed, although part of the information used by PST and MIT is similar (IBD distribution among sib-pairs), which can account for some concordant results, the PST does not

Table 3 Chromosomal regions with evidence for linkage to asthma and/or to BHR at $P \leq 0.005$ with at least one test (PST or MIT) taking into account gene $\times$ passive smoking interaction

\begin{tabular}{|c|c|c|c|c|c|}
\hline \multirow[b]{2}{*}{ Regions } & \multirow[b]{2}{*}{ Position $^{a}$} & \multicolumn{2}{|c|}{ Asthma } & \multicolumn{2}{|c|}{$B H R$} \\
\hline & & PST & MIT & PST & MIT \\
\hline $1 q 43-q 44$ & $263-267$ & - & - & $0.005^{b}$ & 0.0009 \\
\hline $4 q 34$ & 195 & - & - & 0.003 & 0.002 \\
\hline $5 p 15$ & $14-20$ & - & - & 0.003 & 0.02 \\
\hline $14 q 32$ & 108 & - & 0.0009 & - & - \\
\hline $17 \mathrm{p} 11$ & 43 & - & - & 0.002 & 0.002 \\
\hline $17 q 21$ & $64-67$ & - & 0.0003 & - & - \\
\hline
\end{tabular}

Abbreviations: BHR, bronchial hyper-responsiveness; PST, predivided sample test, MIT, Mean Interaction Test.

${ }^{a}$ The distance $(\mathrm{cM})$ from pter retrieved from http://www.marshmed.org/genetics.

${ }^{\mathrm{b}} P$-value,,$- P>0.05$. 
use the IBD distribution among sib-pairs discordant for ETS while the MIT does and the test statistics differ between these two methods.

As mentioned in the Method section, we also considered the passive ETS in-utero and/or in early childhood phenotype, in addition to passive ETS in early childhood. But this led to unchanged results. Indeed, most of the mothers who smoked during pregnancy also continued to smoke during the early childhood of their child. Analyses considering ETS 'in-utero' only were not possible here because of too small sample sizes. We finally also considered ETS in early childhood defined by exposure to mother's cigarette smoking only, assuming it might have a greater impact than father's smoking. However, use of this ETS variable did not lead to detect other regions than those already reported here (results not shown). As for other retrospective studies, ETS exposure may be subject to recall bias. Indeed, we found in the EGEA study, that offspring of parents who had stopped smoking underestimated their ETS during childhood. Also mothers of asthmatic children under-reported their smoking habits when questioned on their children's passive ETS. ${ }^{17}$ This may lead to misclassification of sib-pairs with respect to exposure but it would likely bias results towards the null hypothesis.

None of the regions detected by the present study has been reported by the two previous genomes scans ${ }^{9,10}$ that investigated $\mathrm{G} \times \mathrm{ETS}$ interaction, except for the result evidenced by the PST in the 1q43-q44 region which was $20 \mathrm{cM}$ apart from the peak load in the $1 \mathrm{q} 42$ region reported by the American study. ${ }^{9}$ In particular, we did not confirm linkage of $5 \mathrm{q}$ to asthma or BHR reported by the American and Dutch scans respectively in exposed sib-ships. Discrepancies between these results may be partly due to differences in terms of the affection status examined, asthma only in the American study ${ }^{9}$ and both asthma and BHR in the Dutch ${ }^{10}$ and French studies. Different statistical approaches were also used, a model-based approach in the Dutch study, and model-free approaches in the American and French studies but using different testing procedures. We should also note that tests of $\mathrm{G} \times \mathrm{E}$ interaction are generally conservative, and absence of replication may be also owing to lack of power.

A few regions revealed by the present study have been reported by previous genome screens of asthma and asthma-related phenotypes that did not take into account $\mathrm{G} \times$ ETS interaction (including the EGEA study). The $14 \mathrm{q} 32$ region has shown evidence for linkage to asthma in the Hutterites population $^{25}$ and to IgE in the CSGA study ${ }^{26}$ while the 17q21 was found linked to atopy in EGEA families, ${ }^{27}$ asthma in Australian families ${ }^{28}$ and to atopy in Dutch family data. ${ }^{29}$ With respect to BHR, the $1 \mathrm{q} 43-\mathrm{q} 44$ region was found linked to atopic asthma in a sample of European, Australian and US families, ${ }^{30}$ the $4 \mathrm{q} 34$ region was detected for asthma in that same family sample ${ }^{31}$ and the 5 p15 region was revealed for asthma in the CSGA Afro-
American families ${ }^{32}$ and for atopy in the EGEA study. ${ }^{13}$ All these results underline the complex genetic architecture of asthma for which there may be genes with pleiotropic effects on correlated phenotypes as well as gene-gene and gene-environment interactions.

Overall, all regions revealed by the PST/MIT for asthma and BHR were not detected by previous linkage analyses of these phenotypes that ignored $\mathrm{G} \times \mathrm{E}$ interaction in the same EGEA data. Note, however, that these previous analyses did not use the additional fine mapping markers as done here. However, when repeating linkage analyses of asthma and BHR with these additional markers on chromosomes 1, 5 and 17 (results not shown), linkage to these regions was still not detected except for the $1 \mathrm{q}$ region, which was revealed for BHR but in a less significant manner than presently with the MIT. These results support that taking into account $\mathrm{G} \times \mathrm{E}$ can increase substantially power to detect linkage. Moreover, the PST makes it possible to reveal $\mathrm{G} \times \mathrm{E}$ interaction. However, replication studies are needed to confirm our findings, since only one region on $1 \mathrm{q}$ replicated previous results in CSGA data. ${ }^{9}$ Further identification of these genes within these regions will permit to understand how the interactions of these genes with passive smoking in early life play a role in the development of asthma.

\section{Acknowledgements \\ EGEA Cooperative group}

Coordination: F Kauffmann; F Demenais (genetics); I Pin (clinical aspects).

Respiratory epidemiology: Inserm $U$ 578, Grenoble: $V$ Siroux; Inserm U 700, Paris; M Korobaeff (Egea1), F Neukirch (Egea1); Inserm $U$ 707, Paris: I Annesi-Maesano; Inserm $U$ 780, Villejuif: $F$ Kauffmann, N Le Moual, R Nadif, MP Oryszczyn.

Genetics: Inserm U 393, Paris: J Feingold; Inserm U 535, Villejuif: MH Dizier; Inserm U 794, Evry: E Bouzigon, F Demenais; CNG, Evry: I Gut, M Lathrop.

Clinical centers: Grenoble: I Pin, C Pison; Lyon: D Ecochard (Egea1), F Gormand, Y Pacheco; Marseille: D Charpin (Egea1), D Vervloet; Montpellier: J Bousquet; Paris Cochin: A Lockhart (Egea1), R Matran (now in Lille); Paris Necker: E Paty, P Scheinmann; Paris-Trousseau: A Grimfeld, I Just.

Data and quality management: Inserm ex-U155 (Egea1): J Hochez; Inserm U 780, Villejuif: $N$ Le Moual, C Ravault; Inserm U 794: $N$ Chateigner; Grenoble: J Ferran

We also thank INSERM, the EU Framework programme for research contract $n^{o}$ FOOD-CT-2004-506378, the GA2LEN project, Global Allergy and Asthma European Network, European GABRIEL grant (FP6-LSH-2004-5-018996) and Agence Nationale pour la Recherche grant (ANR 05-SEST-020-02/05-9-97) for their support.

\section{References}

1 Wills-Karp M, Ewart SL: Time to draw breath: asthma-suceptibility genes are identified. Nat Genetics 2004; 5: 376-387.

2 Ober C, Hoffjan S: Asthma genetics 2006: the long and winding road to gene discovery. Genes Immun 2006; 7: 95-100. 
3 Ehrlich RI, Du Toit D, Jordaan E et al: Risk factors for childhood asthma and wheezing. Importance of maternal and household smoking. Am J Respir Crit Care Med 1996; 154: 681-688.

$4 \mathrm{Li}$ YF, Gilliland FD, Berhane $\mathrm{K}$ et al: Effects of in utero and environmental tobacco smoke exposure on lung function in boys and girls with and without asthma. Am J Respir Crit Care Med 2000; 162: 2097-2104.

5 Lanphear BP, Aligne CA, Auinger P, Weitzman M, Byrd RS: Residential exposures associated with asthma in US children. Pediatrics 2001; 107: 505-511.

6 Wang Z, Chen C, Niu T et al: Association of asthma with beta(2)adrenergic receptor gene polymorphism and cigarette smoking. Am J Respir Crit Care Med 2001; 163: 1404-1409.

7 Kabesch M, Hoefler C, Carr D, Leupold W, Weiland SK, von Mutius E: Glutathione $S$ transferase deficiency and passive smoking increase childhood asthma. Thorax 2004; 59: 569-573.

8 Gilliland FD, Li YF, Dubeau L et al: Effects of glutathione S-transferase M1, maternal smoking during pregnancy, and environmental tobacco smoke on asthma and wheezing in children. Am J Respir Crit Care Med 2002; 166: 457-463.

9 Colilla S, Nicolae D, Pluzhnikov A et al: Evidence for geneenvironment interactions in a linkage study of asthma and smoking exposure. J Allergy Clin Immunol 2003; 111: 840-846.

10 Meyers DA, Postma DS, Stine OC et al: Genome screen for asthma and bronchial hyper responsiveness: Interactions with passive smoke exposure. J Allergy Clin Immunol 2005; 115: $1169-1175$.

11 Dizier $\mathrm{MH}$, Selinger-Leneman $\mathrm{H}$, Genin E: Testing linkage and Gene $\mathrm{x}$ Environment interaction: Comparison of different affected sib-pair methods. Genet Epidemiol 2003; 25: 73-79.

12 Selinger-Leneman $H$, Genin E, Norris JM, Khlat M: Does accounting for gene-environment $(\mathrm{GxE})$ interaction increase the power to detect the effect of a gene in a multifactorial disease? Genet Epidemiol 2003; 24: 200-207.

13 Bouzigon E, Dizier MH, Krähenbühl C et al: Clustering patterns of LOD scores for asthma-related phenotypes revealed by a genomewide screen in 295 French EGEA families. Hum Mol Gen 2004; 13: 3103-3113.

14 Dizier MH, Bouzigon E, Guilloud-Bataille M et al: Genome Screen in the French EGEA Study: detection of linked regions shared or not shared by Allergic Rhinitis and Asthma. Genes Immun 2005; 6: 95-102.

15 Morton NE: The detection and estimation of linkage between the genes for elliptocytosis and the Rh blood type. Am J Hum Genet 1956; 8: 80-96

16 Gauderman WJ, Siegmund KD: Gene-environment interaction and affected sib pair linkage analysis. Human Heredity 2001; $5234-5246$.

17 Kauffmann F, Dizier MH, Annesi-Maesano I et al: EGEA (Epidemiological study on the Genetics and Environment of Asthma, bronchial hyperresponsiveness and atopy) - descriptive characteristics. Clin Exp Allergy 1999; 29 (Suppl 4): 17-21.

18 Kauffmann F, Annesi-Maesano I, Liard R et al: Construction et validation d'un questionnaire en épidémiologie respiratoire. L'exemple du questionnaire de l'étude épidémiologique des facteurs génétiques et environnementaux de l'asthme, l'hyperréactivité bronchique et de l'atopie (EGEA). Rev Mal Resp 2002; 19: $323-333$.

19 O'Connell J, Weeks DE: PedCheck: A Program for Identification of Genotype incompatibilities in Linkage Analysis. Am J Hum Genet 1998; 63: 259-266.

20 O'Connell JR, Weeks DE: The VITESSE algorithm for rapid exact multilocus linkage analysis via genotype set-recoding and fuzzy inheritance. Nat Genet 1995; 11: 402-408.

21 Risch N: Linkage strategies for genetically complex traits III. The effect of Marker polymorphism on analysis of affected relative pairs. Am J Hum Genet 1990; 46: 242-253.

22 Suarez BK: The affected sib pair IBD distribution for HLA-linked disease susceptibility genes. Tissue Antigens 1978; 12: 87-93.

23 Holmans P: Asymptotic properties of affected sib-pair linkage analysis. Am J Hum Genet 1993; 52: 362-374.

24 Siroux V, Guilbert P, Le Moual N, Oryszczyn MP, Kauffmann F: Influence of asthma on the validity of reported lifelong environmental tobacco smoke in the EGEA study. Eur J Epidemiol 2004; 19: $841-849$.

25 Ober C, Tsalenko A, Parry R, Cox NJ: A second-generation genomewide screen for asthma-susceptibility alleles in a founder population. Am J Hum Genet 2000; 67: 1154-1162.

26 Mathias R, Freidhoff L, Blumenthal $\mathrm{M}$ et al: Genome-wide linkage analyses of total serum IgE using variance components analysis in asthmatic families. Genet Epidemiol 2001; 20: 340-355.

27 Dizier MH, Besse-Schmittler C, Guilloud-Bataille M et al: Genome screen for asthma and related phenotypes in the French EGEA study. Am J Respir Crit Care Med 2000; 162: 1812-1818.

28 Ferreira MA, O'Gorman L, Le Souef $\mathrm{P}$ et al: Robust estimation of experimentwise $P$-values applied to a genome scan of multiple asthma traits identifies a new region of significant linkage on chromosome 20q13. Am J Hum Genet 2005; 77: 1075-1085.

29 Koppelman GH, Stine OC, Xu J et al: Genome-wide search for atopy susceptibility genes in Dutch families with asthma. J Allergy Clin Immunol 2002; 109: 498-506.

$30 \mathrm{Wjst} \mathrm{M}$, Fischer G, Immervoll T et al: A genome-wide search for linkage to asthma. German Asthma Genetics Group Genomics 1999; 58: $1-8$.

31 Altmuller J, Seidel C, Lee YA et al: Phenotypic and genetic heterogeneity in a genome-wide linkage study of asthma families. BMC Pulm Med 2005; 5: 1

32 A genome-wide search for asthma susceptibility loci in ethnically diverse populations. The Collaborative Study on the Genetics of Asthma (CSGA). Nat Genet 1997; 15: 389-392. 